\title{
Facilitators Improve the Learning Experience of Visitors to a Science Centre
}

\author{
Soledad Machado Corral ${ }^{1,2 *}$, Paulo H. Nico Monteiro ${ }^{3,4}$, Katrina Pisani ${ }^{3}$ and \\ Chantal L. Barriault ${ }^{1}$
}

${ }^{1}$ Faculty of Science, Engineering and Architecture, Laurentian University, Sudbury, ON, Canada, ${ }^{2}$ Facultad de Química, Universidad de la República, Montevideo, Uruguay, ${ }^{3}$ Science North, Sudbury, ON, Canada, ${ }^{4}$ Instituto Butantan, São Paulo, Brazil

\section{OPEN ACCESS}

Edited by:

Dor Abrahamson, University of California, Berkeley, United States

Reviewed by: Josh Gutwill, Exploratorium, United States Zoe Silverman, University of California, Berkeley, United States

*Correspondence:

Soledad Machado Corral smachado@fq.edu.uy

Specialty section:

This article was submitted to STEM Education, a section of the journal Frontiers in Education

Received: 02 March 2021 Accepted: 24 November 2021 Published: 17 December 2021

Citation: Machado Corral S, Monteiro PHN, Pisani K and Barriault CL (2021) Facilitators Improve the Learning Experience of Visitors to a Science Centre.

Front. Educ. 6:675124. doi: 10.3389/feduc.2021.675124
We studied how interactions with interpretative science centre staff impacts the learning behaviours and engagement levels of visitors who engage with exhibits at Science North (Sudbury, Canada). This study uses the Visitor-Based Learning Framework. The tool consists of seven discrete learning-associated behaviours that visitors show when engaging with exhibits, which are grouped into three categories of engagement: Initiation, Transition, and Breakthrough. These categories reflect increasing levels of engagement and depth of the learning experience. We studied forty-seven Science North exhibits, and 4,835 visitors to analyse the impact of unstructured facilitation in a naturalistic setting. We compared visitor Engagement Levels with and without a facilitator present. We determined that the presence of staff has a statistically significant impact on the percentage of visitors that engage in Breakthrough behaviours. When a facilitator is present, more visitors reach the Breakthrough Level of Engagement $(p<0.001)$. In the second phase of the study, we explored what facilitators do and say through thematic analysis to uncover common patterns of facilitator actions and comments. Our findings showed that facilitators employed strategies and methods that can be grouped in four categories or Facilitation Dimensions: Comfort, Information, Reflection, and Exhibit Use. These dimensions encompass different strategies and techniques of facilitation, that are used in a variety of situations and sequences. Our study goes beyond anecdotal evidence to show that staff-visitor interactions have a positive impact on visitor engagement with exhibits and therefore, potentially on visitor learning from exhibits. Our findings can be used to inform not only training programs but also managerial decisions and considerations around resource allocation. We suggest that facilitators are a fundamental asset for institutions that prioritize visitor engagement, one that should be given top priority when considering areas for investing.

Keywords: free choice learning, science centres and museums, facilitators, visitor learning, science centre staff, science centre, informal learning, visitor engagement 


\section{INTRODUCTION}

There is no doubt that learning science is not restricted to spaces and contexts traditionally recognized for this function. Terms like "lifelong learning" emphasize that the learning of concepts, methods and scientific thinking must be understood as a long-term process, throughout life, and much broader than the scope of formal education (Aspin and Chapman, 2000; National Research Council, 2009; Falk and Dierking, 2012; 2018). Among the many opportunities to learn science outside of school settings, museums and science centres have a special place because of their potential to provide meaningful and unique experiences to each visitor (Stocklmayer and Rennie, 2017). These learning spaces are considered "informal" and are often described as environments where one can engage in "free-choice learning" (Falk, 2001; Falk and Dierking, 2012). Free-choice learning tends to be non-linear, since it is driven by the learner's intrinsic needs and interests, and involves considerable choice on the part of the learner as to what, where and when to learn (Falk and Dierking, 2000; Falk, 2001). Informal science education environments have important characteristics that shape the resulting learning experience. Land-Zandstra et al. (2020) summarize informal science education as "often based on voluntary participation; connects to personal interests through a learner-centered approach, lacks formal assessment, and provides opportunities for social interactions with other participants." In addition, the informal setting experience mobilizes a particular set of feelings, sensations and situations that are intrinsically linked to the learning process (Falk and Dierking, 2013). Science centre experiences are often developed to consider visitors' previous knowledge and contribute to the making of meaning around science concepts and ideas (Kirchberg and Tröndle, 2012). Scholars in this field widely agree that understanding how people engage in science diverse contexts, such as science centres, "requires pushing the notion of learning science well beyond the limits of cognitive concepts, and reaching into the realms of interest, enthusiasm, motivation, and the social context of learning" (Rennie, 2012, p. 198).

At its most basic level, a science centre visit involves physically interacting with an array of hands-on exhibits, usually as part of a group (family or school for example). Understanding the role of this interactivity in a visitor's learning experience has been investigated since at least the 1990's (Boisvert and Slez, 1995; Serrel, 1997 for example) and many researchers have since explored aspects of exhibit design that optimize visitor interaction that leads to engagement, contributing to the visitor learning experience (Afonso and Gilbert, 2007; Hohenstein and Tran, 2007; Humphrey and Gutwill, 2005; Allen, 2004 to name a few). More recently, researchers are investigating physical interactions with exhibits to more deeply understand how visitors use their bodies to make sense of science concepts and form a science identity [see for example Shaby and Veder-Weiss (2021) for an exploration of embodiment in informal environments].
Many authors and researchers in informal science education recognize that engagement, as influenced by visitors' prior experience and understanding, is key for meaning making and the construction of knowledge in the science centre setting (Kisiel, 2012; Hauan and Kolstø, 2014; Ocampo-Agudelo and Maya, 2021). Barriault and Pearson (2010) for example, developed a framework that links visitor engagement and learning-associated behaviors to the potential learning impact of an exhibit. Their Visitor-Based Learning Framework (VBLF) draws from constructivist and socio-constructivist learning perspectives (Barriault and Pearson, 2010) and provides science centre practitioners with an exhibit assessment tool that is empirically-driven and rooted in science centre visitor observations.

When investigating the visitor learning experience in freechoice environments, the Contextual Model of Learning proposed by Falk and Dierking (2013) is also a helpful theoretical construct. This model states that a museum visit exists and is constructed in the interplay of three contexts: personal, physical, and sociocultural. The socio-cultural context stems in part from the visitor's culture, beliefs and values, along with their previous ideas of what a museum is and feels like, as an institution. Importantly, the museum experience is mediated by micro-sociocultural interactions with others, including members of their group, other visitors, facilitators, or staff (Falk and Dierking, 2013; 2018). It could be argued that, in the informal science setting, facilitators are uniquely situated to engage with visitors by integrating these three contexts through an invitation to explore and discover the physical setting (a whole floor or a single exhibit) and creating opportunities for social interactions that address the personal context and lead to the making of meaning for the visitor (Pattison and Dierking, 2012; Falk and Dierking, 2013). The informal learning setting enables and provides the space for unstructured social interactions to occur, both among individuals in groups of visitors, and between visitors and facilitators (Land-Zandstra, 2020). Researchers in fact suggest that social interaction promotes dialogue and engagement between the visitor and the exhibit (National Research Council, 2009; Jakobsson and Davidsson, 2012; Patrick and Tunnicliffe, 2013).

As visitors' physical interactions with an exhibit are so often facilitated by science centre or museum staff, researchers have explored the role that facilitators play in that experience (Leinhardt et al., 2003; Lindemann-Matthies and Kamer, 2006; Anderson et al., 2002; Mony and Heilich, 2008; Pattison and Dierking, 2012). For science centre and museum practitioners, assessing the direct impact of a facilitator on visitors' engagement with an exhibit could provide empirical evidence on which to base staffing decisions, with the potential to inform facilitator training. Thus, the purpose of this study is to analyse the impact facilitators have on the level of engagement of visitors as they interact with exhibits using the Visitor-Based Learning Framework (Barriault and Pearson, 2010; Barriault and Rennie, 2019). To complement this investigation, we explore the common patterns of facilitator activity in their interactions with visitors. 


\section{Visitor-Facilitator Interactions in Museums}

Previous studies suggest that visitors have positive feelings about engaging with museum staff (Anderson et al., 2002), and that visitors value interactions with facilitators more than getting information from signs and reading materials (Mony and Heilich, 2008). Furthermore, visitors report that they learn something new more frequently when they interact with facilitators (Lindemann-Matthies and Kamer, 2006). Falk and Dierking (2013) report that "the few studies conducted with casual visitors do suggest that staff positively influence the experience, particularly when they are skilled interpreters, helping to facilitate and make the experience meaningful for visitors" (p. 163). Noticeably, informal or unstructured interactions between facilitators and visitors in museums and science centres encompass a largely unexplored research territory. The majority of studies conducted on visitorfacilitator interactions so far have focused on structured interactions, such as school group tours [Gutwill and Allen, 2012; see Hauan and Kolstø (2014) for a review] or specifically designed and structured programs and exhibit experiences.

Investigations of structured interactions have been carried out extensively at the Exploratorium in San Francisco, where staff facilitate the visitor experience with exhibits or programs designed specifically to encourage inquiry behaviour (Allen and Gutwill, 2009; Gutwill and Allen, 2010; Gutwill and Allen, 2012). More recently, Pattison and Dierking conducted a series of studies exploring unstructured, but controlled, visitor-facilitator interactions. Their research centres mostly on family learning at interactive math exhibits, facilitated by experienced museum educators who are trained in their approach (Pattison and Dierking, 2013; Pattison et al., 2017; Pattison et al., 2018). Specifically, their studies focus on: a. families, b. math exhibits that were intentionally designed to support staff-family interactions through specific "facilitation affordances," and c. experienced facilitators who underwent extra training for these studies (Pattison et al., 2018). While Pattison and Dierking's investigations give very valuable insight into unstructured staffvisitor interactions, their approach is limited in its ability to capture and understand the role of unstructured staff-visitor interactions because of the controlled design of both the exhibits and the facilitator training. There remains a need to study the impact of unstructured facilitator interactions on visitor engagement with exhibits in naturalistic settings, that can be more easily and broadly applied by practitioners in science centres. The Visitor-Based Learning Framework (Barriault and Pearson, 2010; Barriault and Rennie, 2019) is a tool that lends itself to such an investigation.

\section{The Visitor-Based Learning Framework}

Although most researchers agree that science centres are rich learning environments, it can be costly and difficult to evaluate the learning experience (Barriault, 1999). By observing visitors and analysing their interactions and conversations, Barriault (1999) and Barriault and Pearson (2010) directly addressed this concern and developed a practical tool based on constructivist learning theories. In the Visitor-Based Learning

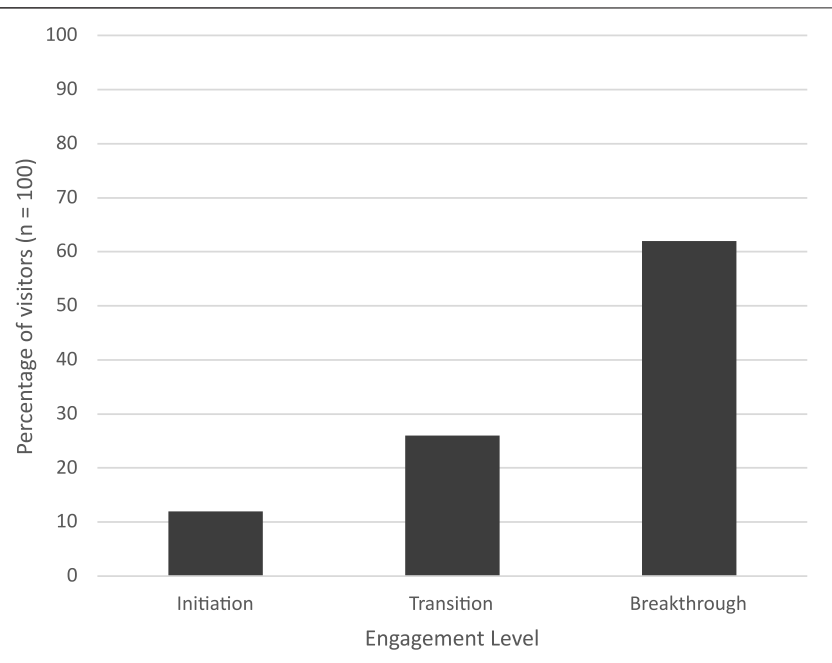

FIGURE 1 | Example of a visitor engagement profile.

Framework, the assessment of the learning taking place is not focused on cognitive gains and instead considers the conditions, processes and engagement that are conducive to learning.

The tool consists of seven discrete learning behaviours that visitors show when engaging with exhibits, which are grouped into three categories of engagement (Initiation, Transition, and Breakthrough). These categories reflect increasing levels of engagement and depth of the learning experience, but do not necessarily occur in a linear fashion (Barriault and Pearson, 2010; Barriault and Rennie, 2019). Initiation behaviours happen when visitors take the first steps in engaging with an exhibit but are not completely involved yet. Transition behaviours are characterized by positive body language and outbursts of emotion. They indicate the visitor is comfortable and is able and willing to engage more thoroughly in the activity. Finally, according to Barriault and Pearson (2010) Breakthrough behaviours reflect a commitment on the part of the visitor to fully engage with the learning opportunities provided by the exhibit; Barriault and Pearson (2010) argue that, in this level of engagement visitors recognize the relevance of the activity (and its associated learning gains) to their own personal life. In this category, it is evident that the visitor is making meaning beyond the purely physical interaction: they build on their previous experience and engage in further exploration and inquiry (Barriault and Pearson, 2010). It is important to point out that the goal of the framework is to assess the potential learning impact of the exhibits. The tool does not focus on visitor characteristics nor does it aim to evaluate visitors' knowledge about the science in the exhibit or the issue discussed (Monteiro et al., 2018).

The percentage of visitors that reach each category can be plotted to produce a visual representation of the potential of an exhibit in engaging visitors, called the Visitor Engagement Profile (VEP, Figure 1).

This assessment tool was developed empirically in science centres (Barriault 1999; Barriault and Pearson, 2010), has been validated (Barriault, 2014) and is recognized as a standardized way to assess the how effective an exhibit is in engaging visitors in a learning 
TABLE 1 | The engagement levels and learning behaviours of the visitor-based learning framework based on Barriault and Pearson (2010). ${ }^{1}$

\begin{tabular}{|c|c|}
\hline Engagement level & Learning behaviours \\
\hline Initiation & $\begin{array}{l}\text { 1. Doing the activity (in passing or completely, but without further exploration) } \\
\text { 2. Observing the exhibit or other visitors engaging in the activity }\end{array}$ \\
\hline Transition & $\begin{array}{l}\text { 3. Repeating the activity to obtain a desired outcome and/or changing variables looking for a difference in outcome } \\
\text { 4. Expressing emotional response in reaction to engaging in the activity, including an excited disposition and verbal reference } \\
\text { to enjoyment }\end{array}$ \\
\hline Breakthrough & $\begin{array}{l}\text { 5. Referring to past experiences while engaging in activity, including making comparisons and deductions based on } \\
\text { observations of similarities and differences } \\
\text { 6. Seeking and sharing information, including having conversations with staff or family members, and reading signage } \\
\text { 7. Being engaged and involved, including testing variables, remaining on task for several minutes, making comparisons, } \\
\text { using information gained from activity }\end{array}$ \\
\hline
\end{tabular}

experience (Barriault and Rennie, 2019; see for example; Shaby et al., 2017; Barriault et al., 2011; Harkins and Harlow, 2011; Visscher and Morrissey, 2010; Schliessmann and Ohding, 2009). Most relevant in the context of our study, Barriault and Pearson (2010) posited that, when comparing facilitated and unfacilitated visitor experiences, "the Visitor Engagement Profiles will reflect the role of floor staff in encouraging a higher level of engagement" (p. 104).

Thus, we investigated the impact that interacting with a facilitator has on visitor behaviour and engagement using the Visitor-Based Learning Framework (VBLF) as our assessment tool. We did this in two phases. In Phase 1, we investigated the impact of visitor-facilitator interactions on visitor engagement. To the best of our knowledge, this is the first study that uses the VBLF as a tool to investigate visitor-facilitator interactions to provide empirical evidence of facilitator impact on visitor engagement and thus, potential learning. Our hypothesis is that an interaction with a facilitator at an exhibit will increase the percentage of visitors that reach the Breakthrough Engagement Level. If that were the case, it is reasonable to suggest that the facilitators interact with visitors in ways that encourage the types of visitor engagement that can lead to learning (Barriault and Pearson, 2010; Barriault and Rennie, 2019). Therefore, in Phase 2 we examined the behaviours of facilitators to better understand the results of the first phase of the study and to describe some characteristics of the facilitator-visitor interactions that can influence visitor engagement and learning.

The research reported here aims to provide clear evidence of facilitator impact on visitor engagement and learning with exhibits in a science centre by answering the following research questions:

RQ1: Do interactions with facilitators at exhibits increase the percentage of visitors that reach the Breakthrough Engagement Level as defined by the VBLF?

RQ2: If so, what are the common types of facilitator behaviours or strategies used when interacting with visitors?

\section{METHODS}

\section{Research Site and its Facilitators}

Science North is the second largest science centre in Canada. It is located in Sudbury, Ontario and opened its doors to the public in 1984. The facilitators in Science North, affectionately known as Blue Coats, are trained to be: "Caretakers" (take care of visitors, ensure surroundings are clean are safe), "Ambassadors" (represent the attributes of the organization, act as a role model to visitors and peers), "Trouble-shooters" (use problem solving skills, are flexible and adaptable, ensure visitors' comfort), "Initiators" (actively engage visitors in science activities), "Scientists" (involve people in the scientific process, eliminate science intimidation, create and promote a sense of wonder), and "Entertainers" (make science fun and understandable through their energy and enthusiasm, be adventurous and spontaneous) (Bray et al., 2011, p.78). These six attributes are known as the "Blue Coat Standards of Excellence."

Science North's exhibit evaluation and research team has years of experience applying the VBLF (Barriault and Pearson, 2010) to assess and improve their exhibits and enhance the visitor experience. Since 2008, the science centre has video recorded and analysed video data to produce Visitor Engagement Profiles for hundreds of individual exhibits. The VBLF and VEP for exhibits are part of the institution's formal exhibit evaluation practices and have become part Science North's organizational measures of success (Barriault et al., 2011; Monteiro et al., 2018).

\section{Pre-Existing Data and its Analysis}

The video data used in our study were previously collected, analysed and coded by Science North researchers using the Visitor-Based Learning Framework (Barriault and Pearson, 2010; Barriault and Rennie, 2019). As the video-recordings of visitors were viewed, research staff from Science North coded visitor behaviours and dialogue using the VBLF as the coding protocol. Table 1 shows the VBLF as it appears in Barriault and Pearson (2010), with Engagement Levels and descriptions of the Learning Behaviours [the reader is directed to Barriault and Pearson (2010), to see the full framework and details of coding protocols]. The coded data include the number of visitors who reach Initiation, Transition and Breakthrough levels of engagement for each exhibit. Importantly for this study, the presence of a facilitator, defined as an instance where a facilitator interacts with one or more visitors at an exhibit, was also coded by Science North researchers. During data collection, Science North staff record the interactions of at least 100 visitors at each exhibit. Ethics protocols are always 
in place for all the recordings and follow the general recommendations of Gutwill (2003). ${ }^{1}$

Our raw dataset consists of approximately $25 \mathrm{~h}$ of coded video and audio recording from the past 12 years (2008-2020), of about 15,000 visitors interacting with 137 exhibits. This vast dataset is a rich source of insight into visitor-facilitator interactions, which had not yet been examined for that purpose. Even though the facilitators were always aware that the exhibit was being recorded to evaluate its learning potential (and that they were consequently recorded along with it), these coded data sets provide an excellent sample of "natural" (as opposed to staged) visitor-facilitator interactions for two reasons: 1 . recordings were not done to evaluate individual facilitators, giving them no reason or incentive to perform a certain way; and 2. according to Science North's research team, facilitators have become familiar with the research activities at the science centre and over time no longer behaved differently as facilitators in the presence of the camera (A. Henson ${ }^{2}$, personal communication, June 24, 2020). Therefore, these videos recorded interactions between facilitators and visitors that are as close as possible to how they occur spontaneously and naturally in a science centre setting.

\section{DATA SELECTION}

\section{Phase 1 - Impact of Facilitation on Visitor Engagement}

The aim of this phase is to investigate the impact of visitorfacilitator interactions on visitor engagement. Of the 137 exhibits that had been previously recorded, coded and analysed, we selected the exhibits that had at least three facilitator interactions in their recorded data, to have a representative sample of visitor-facilitator interaction, and to avoid overestimating the interaction's impact. It is important to note that the research staff at Science North estimate that when exhibits are being recorded, facilitators interact with less than $5 \%$ of visitors, perhaps to avoid interfering with the exhibit's performance as it is being recorded (A. Henson ${ }^{2}$, personal communication, June 24, 2020). Therefore, if an exhibit's data contains fewer than three facilitator interactions, the engagement levels with a facilitator would be determined by that one or two interactions, which could skew the sample and misrepresent the impact the interaction has on the exhibit's VEP. With this criterion of at least three facilitator interactions in the recorded data of an exhibit, our final data sample is comprised of 47 exhibits, and 4,835 total visitors.

To determine if an interaction with a facilitator increases the percentage of visitors reaching the Breakthrough Level of Engagement at an exhibit, we divided all the visitors from all selected exhibits into two groups: those who interacted with a facilitator (with facilitator, $n=439$ ) and those who did not (without facilitator, $n=4,396$ ). We determined the percentage

${ }^{1}$ Table was used with permission from Barriault and Pearson

${ }^{2}$ Senior Scientist, Science Centre Operations and New Audiences, Science North of visitors that reached each Engagement Level (Initiation, Transition, Breakthrough) for each group (with a facilitator, without facilitator).

\section{Phase 2 - Facilitator Strategies and Techniques}

In this phase we examined the verbal and physical behaviours of facilitators to identify and to describe the common activities of the facilitator interactions. We employed qualitative data analysis in the form of emergent patterns or thematic analysis (O'Leary, 2015) of facilitator behaviours in the interaction. We first reviewed all available video from the exhibits studied in Phase 1. Using DaVinci Resolve software, we created separate video segments that showed visitors interacting with facilitators. Each segment begins when the facilitator walks into the space of the exhibit being recorded, or is brought there by a visitor, and ends when the facilitator walks out of that space. This created a pool of 227 visitor-facilitator interactions (approximately $4 \mathrm{~h}$ of footage) which were downloaded as 227 individual segments into NVivo12 for analysis. We applied the protocols of systematic thematic analysis, as described by Braun and Clarke (2006) to our data analysis as follows: The first author reviewed and familiarized themselves with the data while making initial notes and memos about recurring patterns in facilitator behaviour (actions and dialogue), generated initial codes and, began to categorize them into themes. The research team then discussed the emergent codes and themes at length to minimize observer bias, and to verify that the themes that emerged were representative of the data we observed (Braun and Clarke, 2006; Charmaz, 2006). As the research progressed, we systematically identified and compared the different categories of behaviours. We also conducted several rounds of observations to further explore and refine the emergent categories, to further refine and name themes, and to ensure we achieved theoretical saturation (Braun and Clarke, 2006). Since the researchers are experienced facilitators, they consciously brought this perspective to the data analysis when coding facilitator behaviours.

\section{RESULTS}

\section{Phase 1 - Impact of Facilitation on Visitor Engagement}

Figure 3 shows the overall Visitor Engagement Profile for all 47 exhibits combined, with and without facilitator interaction. Facilitator interactions represent between 3 and 27\% ( Mdn = $6 \%$ ) of all visitor - exhibit interactions in this data set of 47 exhibits.

As shown in Figure 2, there is a difference between the two groups for the percentage of visitors in each Engagement Level. For visitors who interacted with a facilitator, the percentage who only reached Initiation is lower $(21.4 \%)$ than for visitors who did not interact with a facilitator $(42.5 \%)$. The percentage of visitors who did not go beyond Transition is virtually the same (28.4 vs. $27.6 \%$ ) for the two groups. Finally, the percentage of visitors who 


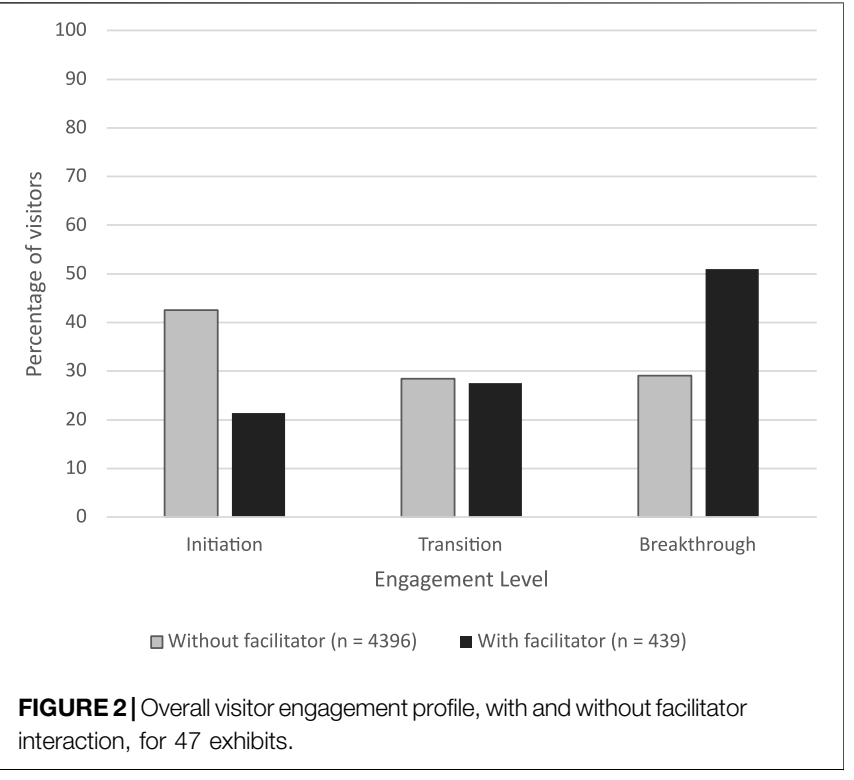

reached Breakthrough is higher (51.0\%) for the visitors who interacted with a facilitator than for visitors who did not $(29.1 \%)$.

The level of engagement is associated with the presence of a facilitator, that is, more visitors reach Breakthrough when a facilitator is present. This association is statistically significant, $\chi^{2}(2, N=4,835)=105.81, p=1.06 \times 10^{-23}$ with a moderate size effect (Cramer's $\mathrm{V}=0.15$ ). Furthermore, there is a moderate positive correlation of $14 \%\left(\tau_{\mathrm{b}}=0.14 \pm 0.06, p=2.60 \times 10^{-24}\right)$ between the presence of a facilitator and the level of engagement.

\section{Phase 2 - Strategies and Techniques}

Four themes of facilitator interaction behaviours emerged from the data: Comfort, Information, Reflection and Exhibit Use. We called them "Facilitation Dimensions" because these actions and comments encompass different strategies and techniques of facilitation.
As a representative example of our thematic data analysis, Table 2 shows a transcript of an interaction between a visitor and a facilitator, with the corresponding codes. In the exhibit studied, visitors use a spinning dial to control the speed of a video of lightning, including the possibility to see it in slow motion. The interaction starts when a visitor, who is interacting with the exhibit, speaks to a facilitator standing a short distance behind.

Tables 3-6 show representative examples of the Facilitator Behaviour for each Facilitation Dimension, including descriptions, and representative examples from the data.

The Comfort Facilitation Dimension describes facilitator behaviours that are welcoming and encouraging to the visitors, making the interaction with the exhibit more pleasant. Table 3 shows the Facilitator Behaviours for this Facilitation Dimension.

The Information Facilitation Dimension includes strategies related to the science content of the exhibit and other information related to this content. Table 4 shows the Facilitator Behaviours for this Facilitation Dimension.

The Reflection Facilitation Dimension encompasses the strategies and techniques used by facilitators to help visitors fully engage with the exhibit, through reflection and making connections. Table 5 shows the Facilitator Behaviours for this Dimension.

Finally, the Exhibit Use Facilitation Dimension includes all strategies and behaviours related to exhibit use, including instructions and tips on how to use the exhibit. Table 6 shows the Facilitator Behaviour for this Dimension.

Table 7 shows the frequency of use of Facilitation Dimensions and Facilitator Behaviours. Frequency is the number of interactions in which strategies from each Dimension were used, not how many times that strategy was used in the same interaction. For example, in the transcript shown in Table 2, the facilitator uses encouraging language twice, laughs twice, calls attention to a phenomena once and gives context and explanation once. When counting for frequencies, this amounts to one instance of "Encouraging language," one instance of "Laughter, joy," one instance of "Calling attention to phenomena" and one

TABLE 2 | Visitor-facilitator interaction transcript with assigned facilitator codes and dimensions.

Visitor (turns to facilitator, pointing at exhibit) Look at that, it's an explosion!

Facilitator Isn't it cool? It is kind of like, kind an explosion, right? It's like all this electricity goes just kkjjjj (explosion onomatopoeia)

Visitor (keeps spinning the dial) Wiiiii!!

Facilitator (laughs)

Visitor (ininteligible)

Facilitator Did you see the one that comes from the bottom? (points at exhibit) Let me see if I can find it. . . (spins the dial) Here we go, this one... It actually comes from--

Visitor --from the ground?

Facilitator From the ground... which is cool, right?

Visitor Yeah

Facilitator How does that happen? There are charges, electrical charges on the ground, often in something like a tower or a tall building, or something like that, like the $\mathrm{CN}$ tower... the charges build up on that and they go up trying to find an opposite charge and it finds it inside the cloud

Visitor That's the big explosion, right?

Facilitator (nods) It's really cool, right? (laughs)

Visitor (nods and leaves)

Encouraging language (Comfort)

Laughter, joy (Comfort)

Calling attention to phenomena (Reflection)

Encouraging language (Comfort)

Giving context and explanation (Information)

Laughter, joy (Comfort) 
TABLE 3 | Comfort facilitation dimension.

\section{Comfort facilitator behaviour}

Encouraging language

Welcoming (greeting, inviting visitor to use the exhibit, general introductory questions)

Laughter, joy (verbal and non-verbal displays of joy)

Focuses on visitor (body language that conveys they are paying attention to the visitor)

\section{Representative examples}

"Great job!"

"That's not quite right, keep trying!"

"Hello, how are you today?"

"Would you like to spin the wheel?"

"So, are you any good at this?"

Laughing out loud

Smiling

Looking people in the eye

Facing people when talking

\section{TABLE 4 | Information facilitation dimension.}

\section{Information facilitator behaviour}

Giving explanation only

Giving context only

Giving explanation AND context

Tells a story

Explaining how the exhibit works

Fun facts

\section{Representative examples}

"The water is evaporating..."

"This would be a lot easier for an elephant, because they have so many muscles in their trunk"

"The arctic is here (points at map) and we are in Sudbury, here" (points at map)

"There are electrical charges on the ground, often in something like a tower or a tall building, or something like that, like the CN tower. . . the charges build up on that and they go up trying to find an opposite charge and it finds it inside the cloud" "So, what's happening with this frog is that it's very sick, so what we've been noticing. . . because this frog lives in Panama, very far away, and they live in mountain tops. . . so, they were disappearing. . . so what they (scientists) did, was they started analysing the frog skin, so now they found that they had a fungus"

"There is an infrared camera there, which allows us to see the heat, things that are cold are blue, things that are hot are red and white"

"An elephant trunk has up to 40,000 muscles!"

TABLE 5 | Reflection facilitation dimension.

Reflection facilitator behaviour

Making connections

Calling attention to phenomena

Proposing a challenge or experiment

Inviting reflection

Asking a trigger question

Asking the visitor for a guess or a hypothesis

\section{Representative examples}

"Do you guys want to see why you're not quite as strong as an orangutan? Follow me!" (takes them to another exhibit) At an exhibit which shows real-time thermal imaging of the visitor, the facilitator brings out a snake and says "that this is how they see their prey"

"The marbles near the centre go faster"

"You can try and build something"

(Visitor 1 interacts with the exhibit, then visitor 2 interacts with the exhibit) "How about together?"

"Why do you think we take eggs from robins' nests?"

"So, how many eggs do you think she laid"

(To a girl looking into a microscope) "Do you know what you're looking at in there?"

"If I were to take an egg from a robin and give it to either a tomtit, a dunnock, or a starling, which one do you think would make the best adoptive parents? ... Why?" instance of "Giving context and explanation". Likewise, this amounts to one instance of the Comfort Dimension, one instance of the Information Dimension and one instance of the Reflection Dimension.

\section{DISCUSSION}

The results show that the presence of a facilitator increases the percentage of visitors who reached Breakthrough levels of engagement as described in the Visitor-Based Learning Framework (Barriault and Pearson, 2010; Barriault and Rennie, 2019). This finding is statistically significant. In addition, the percentage of visitors that only reach Initiation levels of engagement is lower with a facilitator and this finding is also statistically significant. Lastly, the percentage of visitors reaching Transition levels of engagement is almost the same with and without facilitator interaction. Therefore, it can be suggested that the increase in the percentage of visitors that engage in Breakthrough level behaviours comes from the reduction in the percentage of visitors that engage no further than Initiation. These findings, though preliminary, are supported by constructivist and sociocultural models of learning (Falk and Dierking, 2013, 2018), in which learning is recognized as active, highly contextual and social in nature (Hein, 1998; McCallie et al., 2009; National 
TABLE 6 | Exhibit use facilitation dimension.

\section{Exhibit use facilitator behaviour}

Showing how to use the exhibit

Telling how to use the exhibit

Insight into exhibit use

Using the exhibit along with the visitor

Providing technical assistance

\section{Representative examples}

Physically demonstrating how to use the exhibit

"All you do is you squeeze the level and see how strong you are"

"You can also try this, it's fun!"

"For one of them, l'll give you a hint, you have to step back from the table"

Being player 2 on a two-player exhibit

Rebooting the system for an exhibit that has a projector and computer system

\begin{tabular}{|c|c|c|c|}
\hline Facilitation dimension & Frequency & Facilitator behaviour & Frequency \\
\hline \multirow[t]{4}{*}{ Comfort } & 124 & Encouraging language & 59 \\
\hline & & Welcoming & 53 \\
\hline & & Laughter, joy & 33 \\
\hline & & Focuses on visitor & 18 \\
\hline \multirow[t]{5}{*}{ Exhibit use } & 111 & Showing how to use the exhibit & 59 \\
\hline & & Telling how to use the exhibit & 28 \\
\hline & & Insight into exhibit use & 19 \\
\hline & & Using the exhibit along with the visitor & 18 \\
\hline & & Providing technical assistance & 8 \\
\hline \multirow[t]{6}{*}{ Information } & 92 & Giving context and explanation & 45 \\
\hline & & Giving explanation & 24 \\
\hline & & Giving context & 17 \\
\hline & & Tells a story & 15 \\
\hline & & Explaining how the exhibit works & 9 \\
\hline & & Fun facts & 6 \\
\hline \multirow[t]{6}{*}{ Reflection } & 67 & Making connections & 27 \\
\hline & & Calling attention to phenomena & 18 \\
\hline & & Proposing a challenge or experiment & 15 \\
\hline & & Inviting reflection & 15 \\
\hline & & Asking a trigger question & 14 \\
\hline & & Asking the visitor for a guess or a hypothesis & 11 \\
\hline
\end{tabular}

Research Council, 2009; Jakobsson and Davidsson, 2012; Falk and Dierking, 2013, 2018).

The qualitative phase of this study provides further insight into the behaviours and strategies of facilitators that may have contributed to this increase in visitor engagement with exhibits. Our thematic analysis of facilitator behaviours revealed an initial framework that describes the strategies facilitators used when interacting with visitors and consists of four Facilitation Dimensions: Comfort, Information, Reflection, and Exhibit Use. We would like to emphasize that our proposed framework of Facilitator Dimensions is a preliminary categorization of common verbal and behavioural activities displayed by the staff in our data set. Although a more indepth analysis of facilitator-visitor-exhibit interactivity is needed to draw causal relationships between specific facilitator actions and increase in visitor Engagement Levels (Barriault and Pearson, 2010; Barriault and Rennie, 2019), we argue that Facilitator Dimensions are an important contribution to understanding the impact facilitators have on the visitor learning experience with an exhibit.

In our study, the Comfort Dimension is the most frequently used, which may be unsurprising given the importance of welcoming visitors into the exhibit space. If visitors feel uncomfortable, unsafe or unwelcomed, they will likely not engage with exhibits (Barriault and Pearson, 2010) and learning can become challenging because people's basic needs are not being met (Maslow, 1943). The importance of Comfort for facilitator behaviours is supported by previous research that demonstrated that for families, a positive experience with facilitators was associated with a safe, comfortable, and welcoming environment (Brown et al., 2019). By using strategies in the Comfort Facilitation Dimension, we argue that facilitators are showing respect and care for their visitors.

The second most frequently used Facilitator Behaviour Dimension is Exhibit Use which includes actions like explaining how to use an exhibit, using the exhibit alongside the visitor, giving them a tip or a hint, or providing technical assistance. Even considering that our study is independent of individual exhibit characteristics, physically interacting with, or operating the exhibit, plays a key role in the science centre learning experience (Afonso and Gilbert, 2007; Hohenstein and Tran, 2007; Humphrey and Gutwill, 2005; Allen, 2004). When applying strategies from Exhibit Use Facilitation Dimension, we suggest that facilitators are providing added value for visitors, by helping them interact with the exhibit as the basic science centre experience (by providing technical assistance or explaining how to do it) and to go beyond the obvious affordances (by providing tips, hints, or different ways to 
engage with the exhibit), which may lead to visitors spending more time with the exhibit, and having a deeper, more meaningful experience.

The Information Facilitation Dimension describes facilitator behaviours that give visitors more information about the science content of the exhibit, which it can be argued is the typical and expected behaviour of facilitators in science centres and museums (King and Tran, 2017). Delivery and timing are important aspects of the Information Dimension because facilitators should be able to provide information in a way that is not too didactic or expository, and they should also be able to identify when would be the best moment to interact with visitors who are engaging with an exhibit (Brown et al., 2019). Experienced facilitators can determine the best way to engage with each visitor, as this is learned with practice. Learning how to actively listen, observe and respond to visitors in a way that maximizes their opportunities for learning is a sizable task for facilitators (Ash et al., 2012; Patrick, 2017a). The Information Facilitation and the Comfort Dimensions together emphasize the importance of listening, observing and responding to visitors during an interaction.

The Reflection Facilitation Dimension includes facilitator strategies that help visitors fully engage with the exhibit, by inviting (but never ordering or insisting) visitors to reflect on proposed hypotheses, to make connections and to engage in critical thinking. In our study, the Reflection Facilitation Dimension was used the least frequently. We suggest that this may be because these strategies can only be applied when the visitor is already invested in the exhibit and indicates that they are open to delving deeper into the subject, to start thinking about the "why" instead of the "what". Exhibits allow visitors to apply their knowledge and make some connections with their prior knowledge (Kisiel et al., 2012; Hauan and Kolstø, 2014; Ocampo-Agudelo and Maya, 2021), and facilitators can provide opportunities to engage in higher order thinking skills such as those identified by Bloom (1956). Our analysis helped demonstrate that interacting with a facilitator can provide opportunities to "critically evaluate the ideas presented, draw connections among ideas and conjecture, and further investigate phenomena and ideas" (Bloom, 1956, p. 200). Various chapters in Patrick (2017a) underscore this reflection role of facilitation and the importance for informal science educators to be proficient in this skill.

We suggest that these Facilitation Dimensions should all be used in combination to provide a richer learning experience for visitors. In other words, facilitators should apply many different strategies, in a variety of sequences, tailored to each visitor and exhibit. Effective facilitation requires the ability to recognize the visitor's readiness to learn and respond accordingly and in a flexible way (Ash et al., 2012). The Facilitator Dimensions proposed in this study can be understood as guidelines for the initial training of science centre and museum facilitators as they gain experience at engaging visitors with exhibits, and can encourage facilitators to reflect on their practice. Patrick (2017b) promotes reflection as a key component of an informal educator's professional growth and recommends asking themselves questions about their practice such as: "Did I take the time to respond in a meaningful way?"; "Did my response foster a desire in the visitor to find out more information"; "Did my response reflect my knowledge of the subject" and "Will my work with visitors aid them in constructing knowledge?" (Patrick, 2017b, p. 47). The Facilitator Dimensions of our study align with the reflection questions and can provide practical guidance to improve practice.

Importantly, our findings from both Phase 1 and Phase 2 support what other researchers and practitioners have observed with respect to facilitator behaviours. Pattison and Dierking (2013), Pattison et al. (2017) identified five facilitation strategies that have some commonalities with our Facilitation Dimensions. For example, Pattison et al. (2017) found that, when using "Orient" strategies, the facilitator provides visitors with an overview of the exhibit and guidance on how to begin the activity, which overlaps with our Exhibit Use Dimension. Pattison et al. (2017) "Challenges" facilitator behaviour, where the facilitator presents challenges to solve or complete using the exhibit, is encompassed in our Reflection Dimension. Our Information Dimension includes the facilitator behaviour that Pattison et al. (2017) refer to as "Provide Explanations." Finally, Pattison et al. (2017) "Show Appreciation" (congratulating, encouraging or praising visitors) and "Establish Visitor Ownership" (encouraging and supporting visitor control, leadership and agency during the experience) facilitator behaviours are both included in our Comfort Dimension. The series of studies by Pattison and Dierking's (2013), Pattison et al. (2017), Pattison et al. (2018) and our present study focus on unstructured interactions between facilitators and visitors. It is therefore not surprising that there is a great deal of overlap between the facilitation strategies they have identified and the four Dimensions that emerged in our study. These commonalities further validate (Pattison and Dierking's, 2013; Pattison et al., 2017; Pattison et al., 2018) findings and strengthen the authenticity (O'Leary, 2015) of our study. However, the main difference between these investigations, and the contribution of our research, is that our Facilitation Dimensions emerged from the data in a "naturalistic" science centre setting, while in Pattison and Dierking's (2013), Pattison et al. (2017), Pattison et al. (2018) studies, the facilitation methodology and exhibits were iteratively developed and tested to support facilitation. Our study's naturalistic setting and its findings are relevant for science centres that do not have the resources to engage in extensive, iterative facilitation and exhibit design, as those employed by Pattison and Dierking's (2013), Pattison et al. (2017), Pattison et al. (2018). In addition, these Facilitation Dimensions emerged from science centre data collected over 12 years, which included all types of exhibits, and were not limited to specific topics, while Pattison and Dierking's series of studies focused on exhibits tailored for facilitation research and mathematical topics specifically.

The Facilitation Dimensions also unsurprisingly reflect Science North's "Blue Coat Standards of Excellence," as described by Bray et al. (2011). Being "Ambassadors," "Initiators," and "Caretakers" aligns with the Comfort Dimension of Facilitation and may be attributable to the high frequency of such facilitation behaviours in our sample. "Troubleshooting" and "Initiating" are actions that are reflected in the 
Exhibit Use Facilitation Dimension, ensuring that visitors can operate and interact with an exhibit. Being "Entertainers" requires strategies from different Dimensions: the behaviours from the Information and Reflection Dimensions aid the visitors in making meaning of the science, which combined with the strategies from the Comfort Dimension make the experience fun and enjoyable. Finally, being "Scientists" relates to the Information Dimension, by helping the visitor get involved in the scientific process and promote curiosity, for example sharing stories or fun facts. Investigating the relationship between Science North's Blue Coat Standards of Excellence, their facilitator training, and our Facilitation Dimensions could inform future training programs.

\section{Implications for Practice}

Our study goes beyond anecdotal evidence to clearly show that visitorfacilitator interactions have a positive impact on visitor engagement, as defined by Barriault and Pearson (2010) Visitor-Based Learning Framework, when they interact with exhibits. Facilitators are a fundamental asset for science centres and museums and should be given top priority when considering areas for investing. As science centres and museums strive to remain relevant and fiscally responsible, it is crucial to know the tremendous value facilitators bring to achieving institutional education missions. We suggest that the Facilitation Dimensions can be used to inform an institution's facilitator training programs, and be part of assessing facilitator abilities to promote visitor engagement.

This study certainly opens the doors for further research in the field of science centre and museum visitor studies. As mentioned, future studies examining the relationship between training at the study site and our Facilitation Dimensions would be a valuable contribution to the field and one that we intend on pursuing. Future research could also consider investigating what types of exhibits benefit most from facilitation strategies. Some authors have discussed that facilitator interaction might be unwelcome and staff might interfere with visitor learning (Marino and Koke, 2003; Pattison et al., 2018). Understanding this aspect of unstructured interactions should be further explored, since knowing if and when facilitators should engage with visitors

\section{REFERENCES}

Afonso, A. S., and Gilbert, J. K. (2007). Educational Value of Different Types of Exhibits in an Interactive Science and Technology center. Sci. Ed. 91 (6), 967-987. doi:10.1002/sce.20220

Allen, S. (2004). Designs for Learning: Studying Science Museum Exhibits that Do More Than Entertain. Sci. Ed. 88 (S1), S17-S33. doi:10.1002/sce.20016

Allen, S., and Gutwill, J. P. (2009). Creating a Program to Deepen Family Inquiry at Interactive Science Exhibits. Curator: Mus. J. 52 (3), 289-306. doi:10.1111/ j.2151-6952.2009.tb00352.x

Anderson, D., Piscitelli, B., Weier, K., Everett, M., and Tayler, C. (2002). Children's Museum Experiences: Identifying Powerful Mediators of Learning. Curator: Mus. J. 45 (3), 213-231. doi:10.1111/j.2151-6952.2002.tb00057.x

Ash, D., Lombana, J., and Alcala, L. (2012). "Changing Practices, Changing Identities as Museum Educators," in Changing Practices, Changing Identities as Museum Educators. Understanding Interactions at Science Centers and Museums (Rotterdam: Sense Publishers), 23-44. doi:10.1007/978-94-6091725-7_3 would be as valuable as knowing how. Finally, including other research sites from different science centres and museums would contribute to strengthening the validity and reliability of the current findings. It is clear however that, through intentional and purposeful social interactions, facilitators turn museums and science centre exhibits from mere curiosity cabinets into meaning-making experiences that can engage visitors in science learning.

\section{DATA AVAILABILITY STATEMENT}

The compiled data supporting the conclusion of this article will be made available by the authors, without undue reservation.

\section{AUTHOR CONTRIBUTIONS}

$\mathrm{CB}, \mathrm{PM}$, and SM contributed to the conception and design of the study. KP collected and coded the data. SM organized the database, performed the statistical analysis and wrote the first draft of the manuscript. All authors contributed to manuscript revision, read, and approved the submitted version.

\section{FUNDING}

This work was supported by the Agencia Nacional de Investigación e Innovación (ANII, Uruguay) under Grant POS_IDRC_2019_ 1_155393 and by Fundação de Amparo à Pesquisa do Estado de São Paulo (FAPESP, Brazil); Process \# 2019/24361-9.

\section{ACKNOWLEDGMENTS}

We gratefully thank the facilitators and research staff from Science North for their help with this research. In particular, we extend our thanks to Danielle Waltenbury and Amy Henson. The authors wish to thank the Reviewers for their valuable suggestions and contributions.

Aspin, D. N., and Chapman, J. D. (2000). Lifelong Learning: Concepts and Conceptions. Int. J. lifelong Educ. 19 (1), 2-19. doi:10.1080/ 026013700293421

Barriault, C. L. (2014). Visitor Engagement and Learning Behaviour in Science Centres, Zoos and Aquaria. Doctoral dissertation Perth: Curtin University.

Barriault, C. L., and Rennie, L. (2019). The Development of a Standardized Assessment Framework for Animal Exhibits. Visitor Stud. 22 (1), 21-42. doi:10.1080/10645578.2019.1603737

Barriault, C., and Pearson, D. (2010). Assessing Exhibits for Learning in Science Centers: A Practical Tool. Visitor Stud. 13 (1), 90-106. doi:10.1080/10645571003618824

Barriault, C., Pink, J., and Henson, A. (2011). Learning Impact as a Measure of Organizational Success. In 24th Annual Visitor Studies Association Conference. Abstract retrieved from: https://visa.memberclicks.net/assets/ docs/historical/conferences/vsa\%20abstracts\%202011.pdf.

Barriault, C., Pisani, K., and Henson, A. (2011). The Wildlife Rescue Traveling Exhibit: An Evaluation of the Visitor Learning Experience. Unpublished Internal Report. Sudbury, Canada: Science North.

Barriault, C. (1999). The Science centre Learning Experience: A Visitor-Based Framework. Informal Learn. Rev. 35 (1), 14-16. 
Bloom, B. S. (1956). Taxonomy of Educational Objectives: The Classification of Educational Goals. New York, NY: Longmans Green \& Co.

Boisvert, D. L., and Slez, B. J. (1995). The Relationship between Exhibit Characteristics and Learning-Associated Behaviors in a Science Museum Discovery Space. Sci. Ed. 79 (5), 503-518. doi:10.1002/sce.3730790503

Braun, V., and Clarke, V. (2006). Using Thematic Analysis in Psychology. Qual. Res. Psychol. 3 (2), 77-101. doi:10.1191/1478088706qp063oa

Bray, R. M., Mann, D., and St-Onge, M. (2011). Science North: Evolution of a Northern Dream. Sudbury, Ont: Science North/Science Nord.

Brown, R., Jeanneret, N., and Andersen, J. (2019). Are We on the Same page? Family and Museum Staff Perceptions of Engagement and Learning. Visitor Stud. 22 (2), 213-232. doi:10.1080/10645578.2019.1668235

Charmaz, K. (2006). Constructing Grounded Theory: A Practical Guide through Qualitative Analysis. London: SAGE.

Falk, J., and Dierking, L. (2018). Learning from Museums. Walnut Creek, CA: Rowman \& Littlefield.

Falk, J., and Dierking, L. (2000). Learning from Museums: Visitor Experiences and the Making of Meaning. AltaMira Press.

Falk, J. H., and Dierking, L. D. (2012). "Lifelong Science Learning for Adults: The Role of Free-Choice Experiences," in Second International Handbook of Science Education (Dordrecht: Springer), 1063-1079. doi:10.1007/978-14020-9041-7_70

Falk, J. H., and Dierking, L. D. (2013). The Museum Experience Revisited. Walnut Creek, CA: Left Coast Press.

Falk, J. H. (2001). Free-Choice Science Education: How We Learn Science outside of School. Williston, VT: Teachers College Press.

Gutwill, J. P., and Allen, S. (2010). Group Inquiry at Science Museum Exhibits: Getting Visitors to Ask Juicy Questions. 1st ed. Walnut Creek, CA: Left Coast Press.

Gutwill, J. P., and Allen, S. (2012). Deepening Students' Scientific Inquiry Skills during a Science Museum Field Trip. J. Learn. Sci. 21 (1), 130-181. doi:10.1080/ 10508406.2011 .555938

Gutwill, J. P. (2003). Gaining Visitor Consent for Research II: Improving the Posted-Sign Method. Curator: Mus. J. 46 (2), 228-235. doi:10.1111/j.21516952.2003.tb00088.x

Harkins, H., and Harlow, D. B. (2011). "Applying an Observational Framework in Exhibit Evaluation," in Visitor Studies Association Annual Conference, Chicago, ILThe Excitement and Wonder of Teaching Science: What Pre-service Teachers Learn from Facilitating Family Science Night Centers (Chicago: Journal of Science Teacher Education), 23, 199-220.2

Hauan, N. P., and Kolstø, S. D. (2014). Exhibitions as Learning Environments: a Review of Empirical Research on Students' Science Learning at Natural History Museums, Science Museums and Science Centres. NorDiNa 10 (1), 90-104. doi:10.5617/nordina.652

Hein, G. E. (1998). Learning in the Museum. London: Routledge.

Hohenstein, J., and Tran, L. U. (2007). Use of Questions in Exhibit Labels to Generate Explanatory Conversation Among Science Museum Visitors. Int. J. Sci. Edu. 29 (12), 1557-1580. doi:10.1080/ 09500690701494068

Humphrey, T., and Gutwill, J. P. (2005). Fostering Active Prolonged Engagement: The Art of Creating APE Exhibits. Walnut Creek, CA: Left Coast Press.

Jakobsson, E., and Davidsson, A. (Editors) (2012). Understanding Interactions at Science Centers and Museums: Approaching Sociocultural Perspectives (Springer Science \& Business Media).

King, H., and Tran, L. (2017). "Facilitating Deep Conceptual Learning: The Role of Reflection and Learning Communities," in Preparing Informal Science Educators (Cham: Springer), 67-85. doi:10.1007/978-3319-50398-1_4

Kirchberg, V., and Tröndle, M. (2012). Experiencing Exhibitions: A Review of Studies on Visitor Experiences in Museums. Curator: Mus. J. 55 (4), 435-452. doi:10.1111/j.2151-6952.2012.00167.x

Kisiel, J., Rowe, S., Vartabedian, M. A., and Kopczak, C. (2012). Evidence for Family Engagement in Scientific Reasoning at Interactive Animal Exhibits. Sci. Ed. 96 (6), 1047-1070. doi:10.1002/sce.21036

Land-Zandstra, A. M., de Bakker, L., and Jensen, E. A. (2020). "Informal Science Education," in Science Communication: An Introduction, 91-117. doi:10.1142/ 9789811209888_0005
Leinhardt, G., Crowley, K., and Knutson, K. (Editors) (2003). Learning Conversations in Museums (Taylor \& Francis).

Lindemann-Matthies, P., and Kamer, T. (2006). The Influence of an Interactive Educational Approach on Visitors' Learning in a Swiss Zoo. Sci. Edu. 90 (2), 296-315.

Marino, M., and Koke, J. (2003). Face to Face: Examining Educational Staffs Impact on Visitors. ASTC Dimensions. Retrieved from https://web.archive.org/web/ 20100324082946/https://www.astc.org/pubs/dimensions/2003/jan-feb/index.htm.

Maslow, A. H. (1943). A Theory of Human Motivation. Psychol. Rev. 50 (4), 370-396. doi:10.1037/h0054346

McCallie, E., Bell, L., Lohwater, T., Falk, J. H., Lehr, J. L., Lewenstein, B. V., et al. (2009). Many Experts, many Audiences: Public Engagement with Science and Informal Science Education, 1. Washington, DC: A CAISE Inquiry Group Report.

Monteiro, P. H. N., Barriault, C., and Bizzo, N. (2018). The Multiple Roles of Exhibit Learning Impact Assessments in a Science centre. Educere Educare Rev. Ed. 13 (30), 10-17648. doi:10.17648/educare.v13i30.18426

Mony, P. R. S., and Heimlich, J. E. (2008). Talking to Visitors about Conservation: Exploring Message Communication through Docent-Visitor Interactions at Zoos. Visitor Stud. 11 (2), 151-162. doi:10.1080/10645570802355513

National Research Council (2009). Learning Science in Informal Environments: People, Places, and Pursuits. Washington, DC: National Academies Press.

Ocampo-Agudelo, J., and Maya, J. (2021). "July)Core Concepts Linking Exhibit Design and the Visitor Experience in Science Centers: An Early Framework," in International Conference on Human-Computer Interaction (Cham: Springer), 113-130. doi:10.1007/978-3-030-77431-8_7

O'Leary, Z. (2015). The Essential Guide to Doing Your Research Project. 3rd Edition. Los Angeles: SAGE.

Patrick, P. G. (2017b). "Informal Science Educators and the Nine Dimensions of Reflective Practice," in Preparing Informal Science Educators (Cham: Springer), 41-65. doi:10.1007/978-3-319-50398-1_3

Patrick, P. G., and Tunnicliffe, S. D. (2013). Zoo Talk. Dordrecht, Netherlands: Springer.

Pattison, S. A., and Dierking, L. D. (2012). Exploring Staff Facilitation that Supports Family Learning. J. Mus. Edu. 37 (3), 69-80. doi:10.1080/10598650.2012.11510743

Pattison, S. A., and Dierking, L. D. (2013). Staff-mediated Learning in Museums: A Social Interaction Perspective. Visitor Stud. 16 (2), 117-143. doi:10.1080/ 10645578.2013.767731

Pattison, S. A., Randol, S. M., Benne, M., Rubin, A., Gontan, I., Andanen, E., et al. (2017). A Design-Based Research Study of Staff-Facilitated Family Learning at Interactive Math Exhibits. Visitor Stud. 20 (2), 138-164. doi:10.1080/ 10645578.2017.1404348

Pattison, S. A., Rubin, A., Benne, M., Gontan, I., Andanen, E., Shagott, T., et al. (2018). The Impact of Facilitation by Museum Educators on Family Learning at Interactive Math Exhibits: A Quasi-Experimental Study. Visitor Stud. 21 (1), 4-30. doi:10.1080/10645578.2018.1503879

P. G. Patrick (Editor) (2017a). Preparing Informal Science Educators: Perspectives from Science Communication and Education (Columbus: Springer).

Rennie, L. J. (2012). "The Practice of Science and Technology Communication in Science Museums," in Communication and Engagement with Science and Technology: Issues and Dilemmas: A Reader in Science Communication. Editors J. Gilbert and S. Stoklmayer (London: Routledge), 197-212.

Schliessmann, S., and Ohding, N. (2009). "How Can We Research Visitor Interactions with Exhibits," in Science Centre Netzwerk's Symposium: Research on Interactive Exhibits. Available at: https://www.sdu.dk/-/media/ files/om_sdu/centre/c_lsul/skriftserie/nnorsc.pdf.

Serrell, B. (1997). Paying Attention: The Duration and Allocation of Visitors' Time in Museum Exhibitions. Curator: Mus. J. 40 (2), 108-125. doi:10.1111/j.21516952.1997.tb01292.x

Shaby, N., Assaraf, O. B.-Z., and Tal, T. (2017). The Particular Aspects of Science Museum Exhibits that Encourage Students' Engagement. J. Sci. Educ. Technol. 26, 253-268. doi:10.1007/s10956-016-9676-7

Shaby, N., and Vedder-Weiss, D. (2021). Embodied Interactions in a Science Museum. Sci. Educ. 105 (5), 938-960. doi:10.1002/sce.21666

Stocklmayer, S. M., and Rennie, L. J. (2017). "The Attributes of Informal Science Education: A Science Communication Perspective," in Preparing Informal 
Science Educators: Perspectives from Science Communication and Education (Springer), 527-544. doi:10.1007/978-3-319-50398-1_26

Visscher, N., and Morrissey, C. (2010). "Use and Effectiveness of Discovery Carts at the Pacific Science Center," in Visitor Studies Association Annual Conference (Phoenix, AZ.

Conflict of Interest: The authors declare that the research was conducted in the absence of any commercial or financial relationships that could be construed as a potential conflict of interest.

Publisher's Note: All claims expressed in this article are solely those of the authors and do not necessarily represent those of their affiliated organizations, or those of the publisher, the editors and the reviewers. Any product that may be evaluated in this article, or claim that may be made by its manufacturer, is not guaranteed or endorsed by the publisher.

Copyright $\odot 2021$ Machado Corral, Monteiro, Pisani and Barriault. This is an openaccess article distributed under the terms of the Creative Commons Attribution License (CC BY). The use, distribution or reproduction in other forums is permitted, provided the original author(s) and the copyright owner(s) are credited and that the original publication in this journal is cited, in accordance with accepted academic practice. No use, distribution or reproduction is permitted which does not comply with these terms. 